\title{
Effects of substrate temperature on the properties of the indium tin oxide thin films deposited by sputtering method
}

\author{
Chia-Ching $\mathrm{Wu}^{1, *}$ and Chien-Chen Diao ${ }^{2}$ \\ ${ }^{1}$ Department of Applied Science, National Taitung University, Taitung, Taiwan, R.O.C. \\ ${ }^{2}$ Department of Electronic Engineering, Kao Yuan University, Kaohsiung, Taiwan, R.O.C.
}

\begin{abstract}
High-quality transparent conductive indium tin oxide (ITO) thin films were deposited on glass substrates using radio frequency sputtering method. The structure and electrical and optical properties of the ITO thin films were mainly investigated. The ITO thin films showed strong diffraction peak having a preferred orientation along the [111] direction as the deposition temperature at 120 to $160{ }^{\circ} \mathrm{C}$. In the transmission spectra, the optical transmittance increased in the visible range as the deposition temperature increased from RT to $160{ }^{\circ} \mathrm{C}$. A minimum resistivity of $3.06 \times 10^{-3} \Omega$-cm was obtained for the ITO thin film deposition at $160{ }^{\circ} \mathrm{C}$.
\end{abstract}

\section{Introduction}

Transparent conducting oxide (TCO) thin films, such as tin oxide $\left(\mathrm{SnO}_{2}\right)$, indium tin oxide (ITO), zinc oxide ( $\mathrm{ZnO}$ ), indium zinc oxide (IZO), gallium zinc oxide (GZO) and indium gallium zinc oxide (IGZO), are used for a wide range of important applications, such as transparent electrodes in light-emitting diode (LED) [1], organic light-emitting devices (OLED) [2], liquid crystal display (LCD) [3] and solar cell [4] applications. Among the TCO thin films, indium oxide doped with tin (ITO) is widely used due to its unique electrical and optical properties such as good conductivity (about $10^{4} \Omega^{-1} \mathrm{~cm}^{-1}$ ) and high transmittance $(\sim 85 \%)$ in the visible region due to its large bandgap of about $3.70 \mathrm{eV}$ [5].

ITO thin film has been prepared by various techniques, such as pulsed laser deposition [6], radio-frequency (RF) magnetron sputtering [7], the sol-gel method [8], and electron beam evaporation [9] and spray pyrolysis [10]. Various growth conditions have the effect of increment in the carrier concentrations contributing to the enlargement of the bandgap, which is known as the Burstein- Moss shift [11]. RF magnetron sputtering is widely used because it is considered to be one of the best methods for preparing ITO thin film with high quality. In this study, ITO thin films of a fixed composition $\left(\mathrm{In}_{2} \mathrm{O}_{3}=90 \mathrm{wt} \%\right.$ and $\mathrm{SnO}_{2}=10$ wt $\%$ ) were deposited on the glass substrate with different substrate temperature by RF magnetron sputtering. The structural, optical, and electrical properties of the ITO thin films were characterized by scanning electron microscopy (SEM), X-ray diffraction (XRD) pattern, UV-visible spectroscopy, and Hall measurement.

*Corresponding author: ccwu@nttu.edu.tw 


\section{Experimental procedures}

Indium tin oxide thin films were deposited on glass substrates with a $\operatorname{In}_{2} \mathrm{O}_{3}: \mathrm{SnO}_{2}(90$ : $10 \mathrm{wt} \%$ ) ceramic target (Summit-Tech. Co.) of $99.99 \%$ purity by using radio frequency (R.F.) magnetron sputtering system, as shown in Fig. 1. The glass substrate was cut into a square shape $20 \mathrm{~mm} \times 20 \mathrm{~mm}$ in size. The prepared glass substrate was cleaned ultrasonically in acetone, ethanol and IPA for 20 minutes and finally rinsed in distilled water. The working distance between the substrate and target was fixed at $12 \mathrm{~cm}$. A heater was used for substrate heating from 120 to $160{ }^{\circ} \mathrm{C}$. The temperature was obtained by a thermocouple on the substrate surface and was controllable with $1 \%$ measurement accuracy. The working pressure was set to $5 \times 10^{-3}$ torr and the R.F. power varied from $40 \mathrm{~W}$ to $120 \mathrm{~W}$. The surface morphology and thickness of the ITO thin films were measured by using the field emission scanning electron microscope (FE-SEM). The crystalline structural characterization of the ITO thin films was carried out by an x-ray diffractometer (XRD) using $\mathrm{Cu} \mathrm{K} \alpha$ radiation $(\mathrm{K} \alpha=0.15418 \mathrm{~nm})$. The optical transmission was taken in the wavelength range of 200 $1100 \mathrm{~nm}$ using a Hitachi U-2900 model UV/Vis spectrophotometer. The resistivity $(\rho)$, carrier concentration $\left(n_{\mathrm{e}}\right)$ and carrier mobility $(\mu)$ were obtained from Hall-effect measurements using the Van der Pauw method.

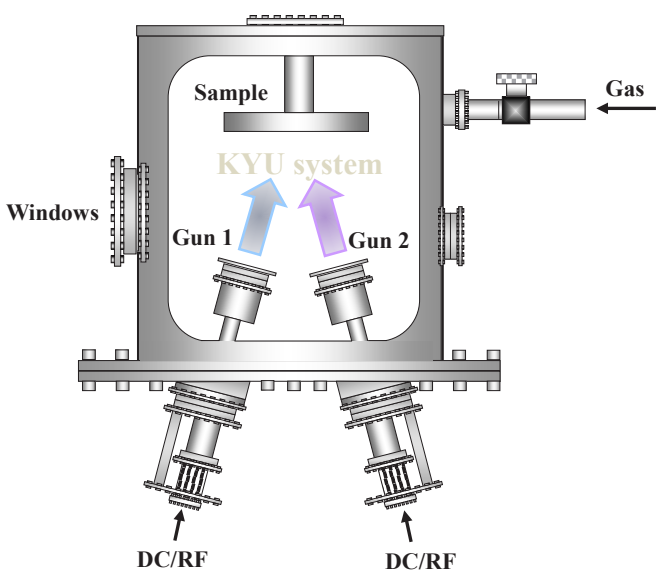

Fig. 1. The diagram of the radio frequency magnetron sputtering system.

\section{Results and discussion}

XRD patterns of the ITO thin films with different deposition powers are shown in Fig. 2. As the ITO thin film deposition at room temperature, it shows an amorphous structure and the ITO thin films are polycrystalline structure as the substrate temperature at $120^{\circ} \mathrm{C}$ to $160{ }^{\circ} \mathrm{C}$. As the substrate temperature increases to $120{ }^{\circ} \mathrm{C}$ to $160{ }^{\circ} \mathrm{C}$, all patterns exhibited the (211), (222), (400), (400) and (620) peaks of the ITO thin films at diffraction angles $(2 \theta)$ near $21.2^{\circ}, 30.3^{\circ}, 34.8^{\circ}, 50.3^{\circ}$ and $59.9^{\circ}$, respectively. The obtained diffraction peaks were in accordance with the standard JCPDS data (Card no. 65-3170). And no any second phase was obtained in the patterns. In addition, the intensity of the (222) diffraction peak increased as the substrate temperature increased from $120{ }^{\circ} \mathrm{C}$ to $160{ }^{\circ} \mathrm{C}$. The fact that the spectra showed a diffraction peak of (222) means that the prepared films had a tendency to crystallize along the preferred orientation of [111] direction. From above results, the crystallization of the ITO thin films is enhanced as higher deposition temperature is used, 
for that the resistivity of the ITO thin films will closely depend on the deposition temperaature.

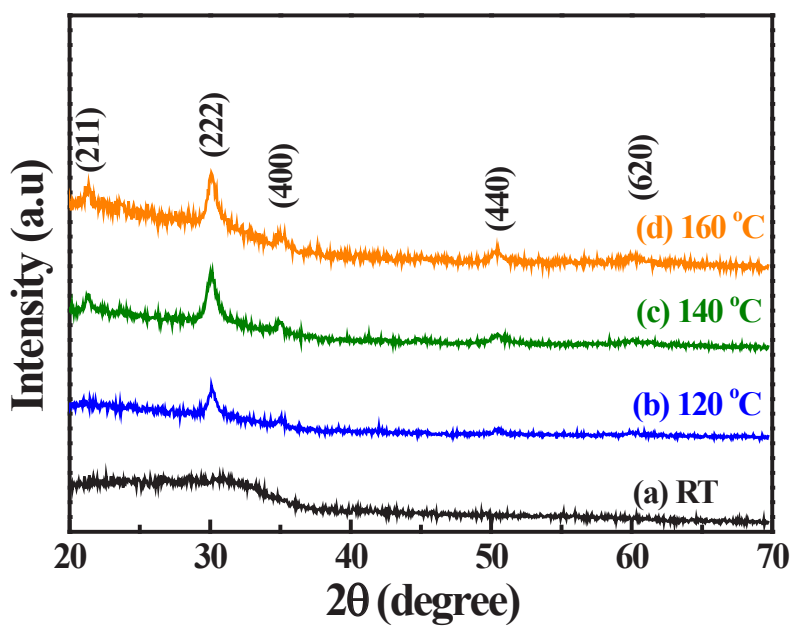

Fig. 2. XRD analysis of the ITO thin films as a function of deposition temperature. (a) RT, (b)120, (c) 140 and (e) $160^{\circ} \mathrm{C}$, respectively.

Figures 3 and 4 shows the top-view and cross-sectional SEM image of the ITO thin films prepared at various substrate temperatures. The film prepared at room temperature exhibits non-crystalline structure as shown in Fig. 3(a), and he surfaces of the ITO thin film are smooth and compact. Compared with the ITO thin film deposition at RT, the top-view micrographs of the $120{ }^{\circ} \mathrm{C}$-, $140{ }^{\circ} \mathrm{C}$-, and $160{ }^{\circ} \mathrm{C}$-deposited ITO thin films had the similar morphologies, but the grain sizes slightly increased as the deposition temperature increased, as shown in Figs. 2(b)-2(d).
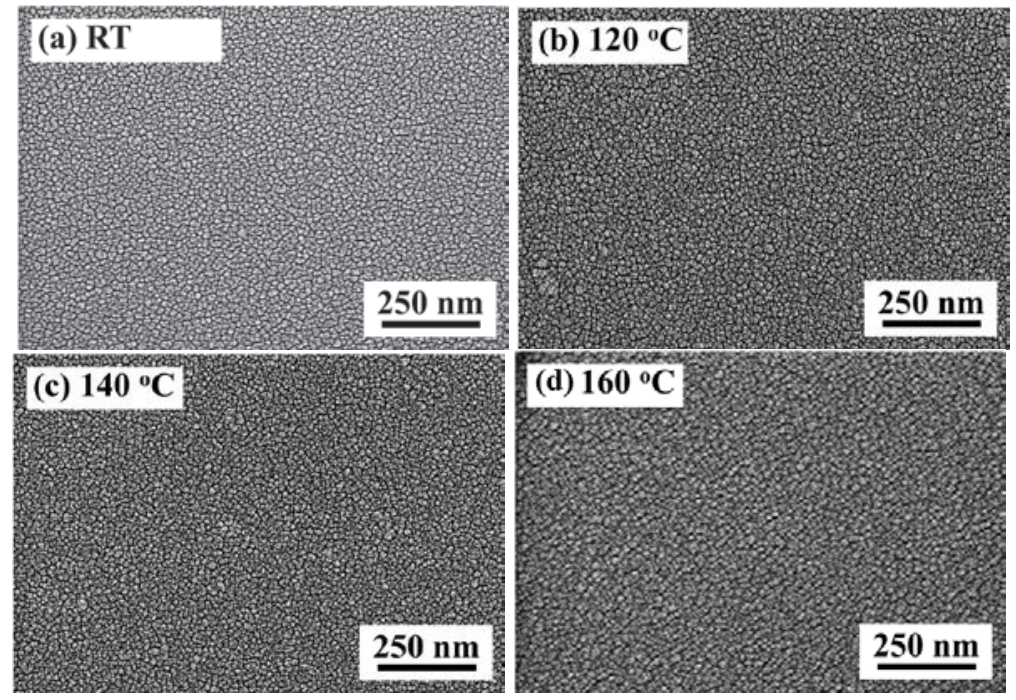

Fig. 3. Top-view SEM observations of the ITO thin films as a function of deposition temperature. (a) RT, (b) 120 , (c) 140 and (e) $160{ }^{\circ} \mathrm{C}$, respectively. 
Figure 4 shows the thickness of the ITO thin film as a function of deposition temperature. The thickness of ITO thin films increased with deposition temperature is considerable. It found that all the ITO thin films had a tendency to crystallize along the preferred orientation of [111] direction. The thickness increased from 125 to $288 \mathrm{~nm}$ as the deposition temperature increased from RT to $160{ }^{\circ} \mathrm{C}$, as shown in Fig. 5 .
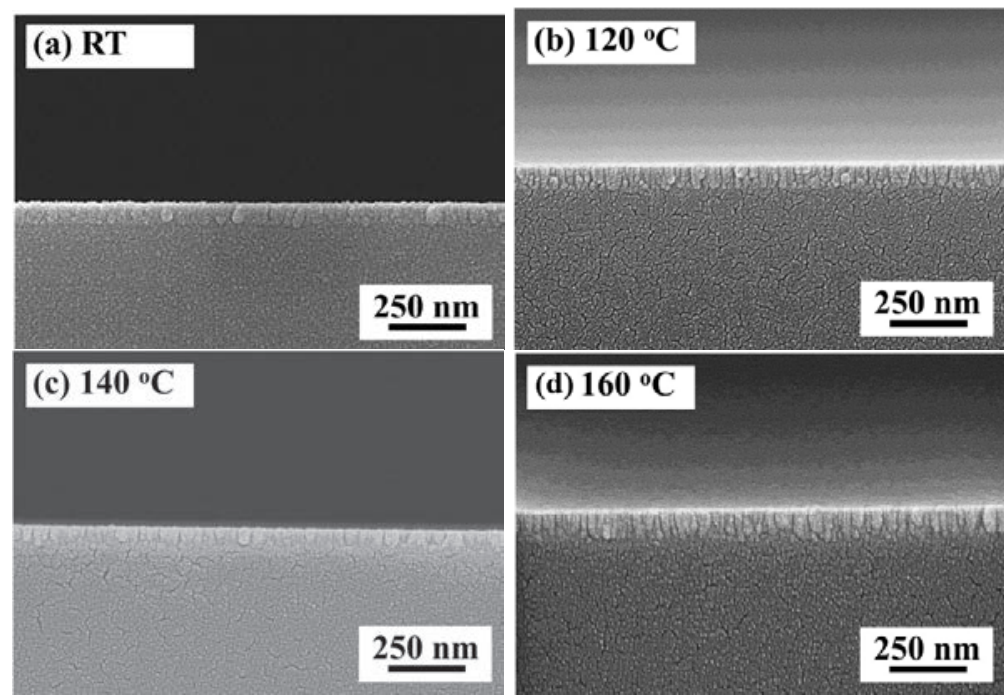

Fig. 4. Cross-sectional SEM observations of the ITO thin films as as a function of deposition temperature. (a) RT, (b) 120 , (c) 140 and (e) $160{ }^{\circ} \mathrm{C}$, respectively.

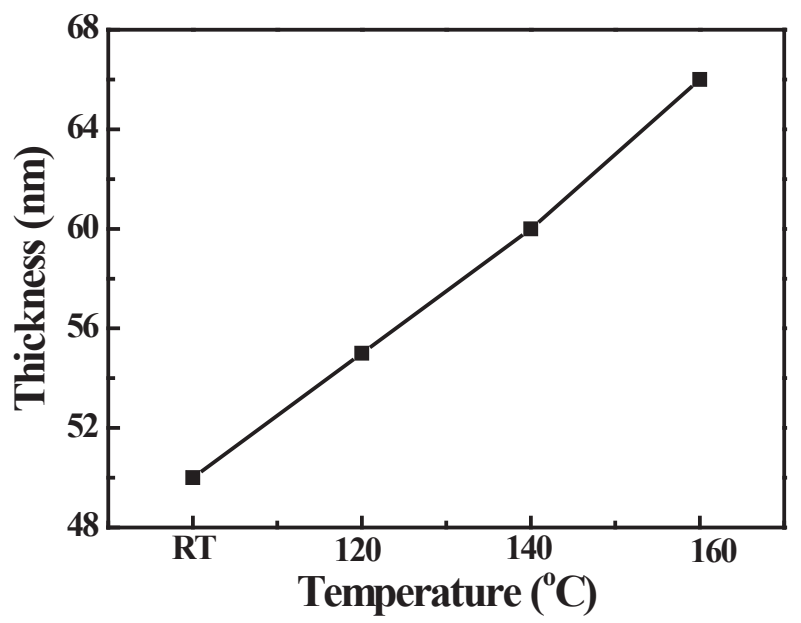

Fig. 5. Thickness of the ITO thin films as a function of deposition temperature.

Figure 6 shows the UV/Vis optical transmittance spectra of the ITO thin films recorded within the wavelength range of the $250-1100 \mathrm{~nm}$. It was found that the transmittance in the visible range increased with increasing substrate temperature, and that the absorption edge was at about $320 \mathrm{~nm}$. The average transmittance of the ITO thin film is about $89.9 \%$ in the 400 to $700 \mathrm{~nm}$ range and $89.3 \%$ at $550 \mathrm{~nm}$ as deposition at room temperature. The average transmittance $(400$ to $700 \mathrm{~nm})$ of the ITO thin films slightly increased from $90.13 \%$ to $91.71 \%$ as deposition temperature increased from 120 to $160{ }^{\circ} \mathrm{C}$. This result caused by the transmittance is closely related to a scattering effect. It is 
considered that an increase in substrate temperature accelerated the degree of crystallization. Accordingly, the microstructure with the crystallization had a higher value of the transmittance by reducing the light scattering in the film [12].

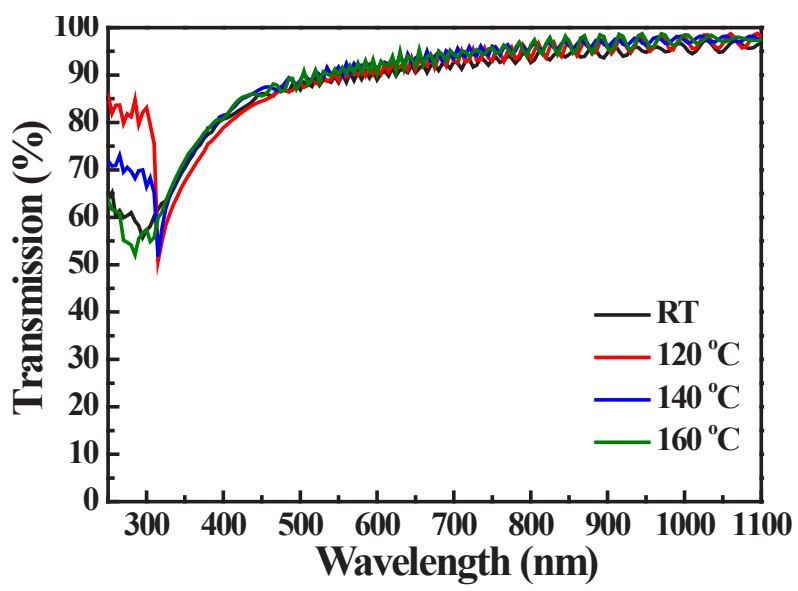

Fig. 6. UV-Vis spectra of the ITO thin films as a function of deposition temperature.

Figure 7 shows the resistivity, mobility and carrier concentration of the ITO thin films as a function of deposition temperature. As the deposition temperaature increased from RT to $160{ }^{\circ} \mathrm{C}$, the mobility decreased from 22.3 to $14.5 \mathrm{~cm}^{2} / \mathrm{V}$-s. From the XRD and SEM results, the ITO thin film deposition at room temperature shows an amorphous structure and the less grain boundary exist in the film. However, the number of grain boundary of the ITO thin films increaseed and leading to an decrease in carrier mobility as the deposition temperaature increased from 120 to $160{ }^{\circ} \mathrm{C}$. The resistivity decreased with increase in substrate temperature. The decrease in resistivity with increase in substrate temperature can also be explained by the fact that the grain size increases significantly with the increase in deposition temperature and increasing conductivity. The carrier concentration of ITO thin films slightly increased from $2.06 \times 10^{19}$ to $1.99 \times 10^{20} \mathrm{~cm}^{-3}$ as the deposition temperature increased from RT to $160^{\circ} \mathrm{C}$.

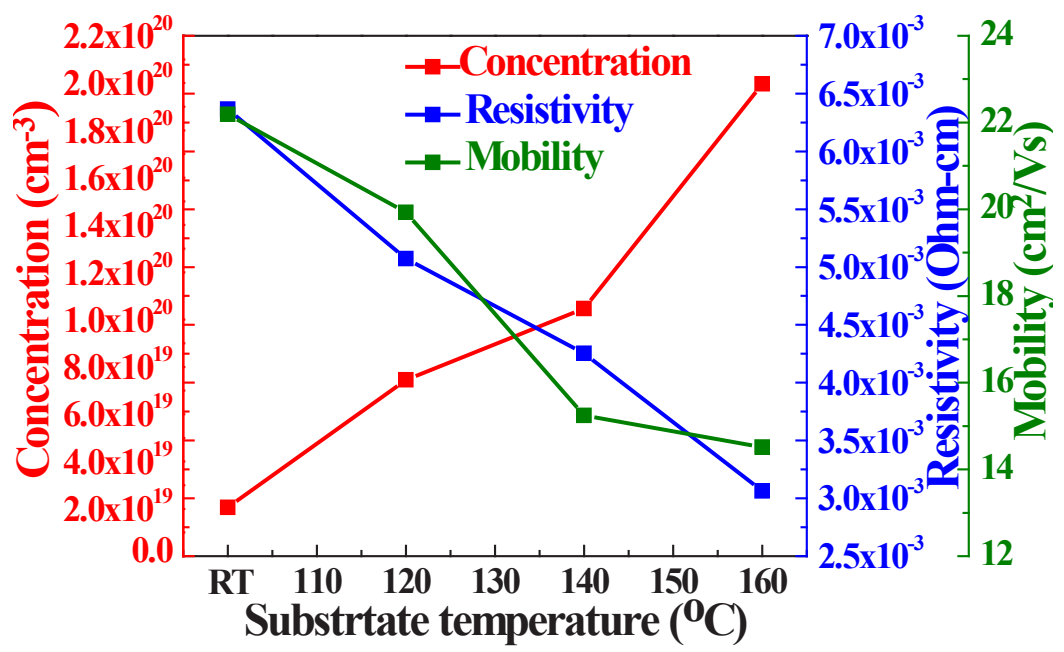

Fig. 7. Resistivity, Hall mobility, and carrier concentration of the ITO thin film as a function of deposition temperature. 


\section{Conclusions}

In this study, crystalline the ITO thin films were deposited on glass substrates using R.F. magnetron sputtering technique as the deposition temperature at 120 to $160{ }^{\circ} \mathrm{C}$. The resistivity of ITO thin films decreased from $6.36 \times 10^{-3}$ to $3.06 \times 10^{-3} \Omega$-cm with increasing in the deposition temperature, which could be explained by a grain size increases significantly with the increase in deposition temperature. The transmittance $(400-700 \mathrm{~nm})$ of the ITO thin films increased with an increase in the substrate temperature. Based on the above results obtained in this study, the ITO thin film was found to be important for future work on electron devices.

\section{Acknowledgment}

The authors acknowledge the financial support of the Ministry of Science and Technology of the Republic of China (MOST 106-2221-E-143-008- and 106-2622-E-143-002-CC3).

\section{References}

1. J. Gu, Z. Xiao, M. Xu, G. Wang, Z. Lu, S. Huang, J. Phys. Chem. Solids, 59, 27 (1998)

2. Y.S. Tsai, F.S. Juang, T.H. Yang, M.C. Yokoyama, L.W. Ji, Y.K. Su, J. Phys. Chem. Solids, 69, 764 (2008)

3. M. Gaillet, L. Yan, E. Teboul, Thin Solid Films, 516, 170 (2007)

4. S. Marikkannu, M. Kashif, N. Sethupathy, V.S. Vidhya, Shakkthivel Piraman, A. Ayeshamariam, M. Bououdina, Naser M.Ahmed, M. Jayachandran, Mater. Sci. Semi. Process., 27, 562 (2014)

5. W. Wohlmuth, I. Adesida, Thin Solid Films, 479, 223 (2005)

6. F. O. Adurodija, L. Semple, R. Br€uning, J. Mater. Sci., 41, 7096 (2006)

7. K. J. Patel, M. S. Desai, C. J. Panchal, J. Mater. Sci. Mater. Electron., 22, 959 (2011).

8. S. Kundu, P. K. Biswas, Chem. Phys. Lett., 414, 107 (2005)

9. Z. Xu, P. Chen, Z. Wu, F. Xu, G. Yang, B. Liu, C. Tan, Z. Xu, L. Zhang, R. Zhang, Y. Zheng, J. Mater. Sci. Mater. Electron., 25, 2287 (2014)

10. Z.B. Zhou, R.Q. Cui, Q.J. Pang, Y.D. Wang, F.Y. Meng, T.T. Sun, Z.M. Ding, X.B. Yu, Appl. Surf. Sci., 172, 245, (2001)

11. V. S. Reddy, K. Das, A. Dhar, S. K. Ray, Semicond. Sci. Technol. 21, 1747, 2006

12. B. R. Cho, Solid State Phenomena, 124, 195 (2007) 